\title{
The effect of microstructure on wear modes of ceramic materials*
}

\author{
O. O. Ajayi ${ }^{\dagger}$ and K. C. Ludema \\ Mechanical Engineering Department, The University of Michigan, Ann Arbor, MI 48109 (USA)
}

(Received August 8, 1991; accepted October 8, 1991)

\begin{abstract}
The effect of the microstructure on the wear modes in structural ceramic materials was studied in two $\mathrm{SiC}$ and three $\mathrm{Al}_{2} \mathrm{O}_{3}$ materials. In each class of materials, it was observed that the predominant damage mode is determined by the microstructure of the material. The materials with weak grain boundaries were found to wear primarily by grain pluckout and so showed more wear than did (the one, $\alpha-\mathrm{SiC}$ ) materials with stronger grain boundaries. In addition, the presence of a softer second phase around the grain boundary, which in commercial materials is usually more ductile than the grain, changed the mode and amount of damage, resulting in improved wear resistance (only in repeated passes). Under repeat pass sliding, the amount of wear increased considerably in all the materials except the material with a softer second phase.
\end{abstract}

\section{Introduction}

The wear resistance of ceramic materials is usually thought to be connected with certain of their commonly measured properties. There are several equations or mathematical formulations that incorporate these material properties, but none of them adequately explains the experimental observations. Perhaps the most widely quoted equation is that of Evans and Marshall [1] in which the wear rate or volume $V$ is related to the relevant variables as follows:

$V=\alpha \frac{E^{0.3}}{K_{\mathrm{s}}^{0.5} H^{1.4}}$

where $E$ is Young's modulus, $K_{c}$ is the stress intensity factor and $H$ is the hardness. The inapplicability of this equation is widely acknowledged (see e.g. refs. 2 and 3 ) and yet it is appealing. It is difficult to sort out the role or significance of each of the variables in the above equation because it is virtually impossible to devise experiments in which only one of the variables is changed without changing some other property of the material. It is not sufficient to hold the other two variables constant because this equation evidently does not incorporate all relevant variables. For example, the ductility of the ceramic material is not included although the importance of ductility is implicit in the model of the above equation. Plastic flow has been observed by many

*Paper presented at the International Conference on Wear of Materials, Orlando, FL, USA April 7-11, 1991.

${ }^{\dagger}$ Currently with the MCT division, Argonne National Laboratory, Argonne, IL 60439, USA. 
investigators during wear in several ceramic materials (see e.g. refs. 4-6) and thus its role cannot be ignored.

The inapplicability of the above equation is seen in two other ways. First, the stress state that leads to failure, and therefore to wear in the contact region between two sliders, is not necessarily the same as in the tests from which the data $K_{\mathrm{c}}, H$, and $E$ are taken. It is known that the imposed stress state significantly affects the mechanical behavior of material. Secondly, the stress state in the contact region is strongly influenced by friction but this is not included in the above formulation. It has been shown $[7,8]$ that the damaging tensile component of sliding contact stresses is intensified by a factor of

$1+\frac{3 \pi(4+\nu)}{8(1-2 \nu)} \mu \approx 1+12 \mu$ for $\nu=0.3$

where $\mu$ is the coefficient of friction and $\nu$ is Poisson's ratio.

Thirdly, there is no provision for fatigue in any of these equations, which is known to be important in ceramic wear. The equations are based on the basic assumption that wear occurs by brittle propagation of radial and lateral cracks that form during contact.

In addition to the above issues, it is likely that the microstructure of the material is as important as the properties, as has been adequately demonstrated in metals. This is very important in the study of ceramic materials because there are often several variations (microstructurally) commercially available of the same generic class of material. This paper is a report of a study of the latter topic, i.e. the effect of the microstructure. The primary focus is on the damage mode resulting from contact and, as such, test conditions were chosen to minimize the effect of other phenomena (such as chemical reaction and frictional heating) that are known to occur during sliding wear.

\section{Experimental details}

\subsection{Materials}

Five commercial ceramic materials from two generic groups, $\mathrm{SiC}$ and $\mathrm{Al}_{2} \mathrm{O}_{3}$, were selected for this research. The rationale for the use of commercial materials rather than specially "tailored" materials is that these have already been optimized for several specific uses. These materials therefore embody the range of properties that are most in need of enhancement for improved products. They also demonstrate the range of properties available within generic types of ceramics. The major differences within each group are the additives used as "sintering aids" (the function of which extends well beyond the formulation stage) and the method for consolidation of the materials. For example, the two sintering aids in the $\mathrm{SiC}$, namely $\mathrm{Al}$ and $\mathrm{B}$ in this case, are intended to increase the diffusion rate in the covalent $\mathrm{SiC}$ and improve intergranular bonding. The $\mathrm{MgO}$ in two of the $\mathrm{Al}_{2} \mathrm{O}_{3}$ materials serves as much to control the regularity of grain size as to aid intergranular bonding. In four of these materials, the amount of additive is within the solubility limits in the grains. The fifth material is $\mathrm{Al}_{2} \mathrm{O}_{3}$ with a $5 \%$ total of $\mathrm{SiO}_{2}+\mathrm{MgO}+\mathrm{CaO}$, which produces a distinct glassy phase that surrounds the grains of $\mathrm{Al}_{2} \mathrm{O}_{3}$. Figures 1 and 2 show the microstructure of the $\mathrm{SiC}$ and $\mathrm{Al}_{2} \mathrm{O}_{3}$ materials respectively.

The composition and properties of the ceramic materials are given in Table 1. In addition to conventional properties, some other distinctions are given between the five listed materials. For example, in the $\mathrm{SiC}$ materials, $\mathrm{SiC}-1$ contains a small amount 


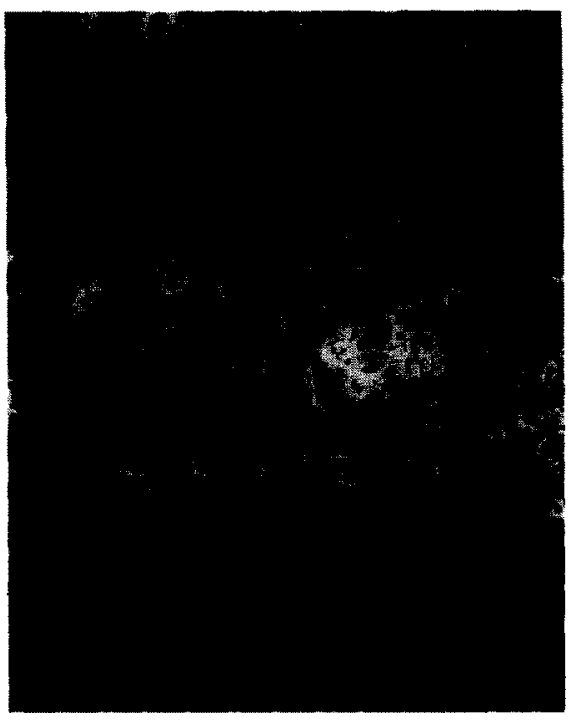

(a)

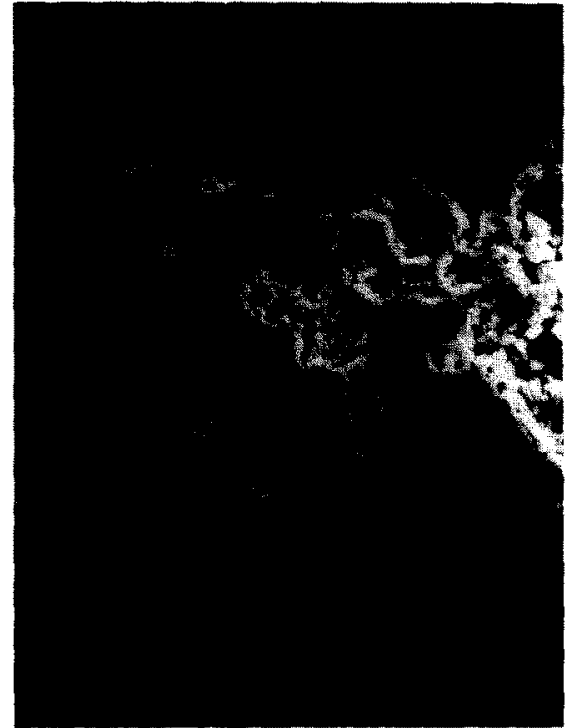

(b)

Fig. 1. SEM micrograph of the microstructure of the SiC materials: (a) hot-pressed material and (b) pressureless sintered material.

of aluminum which generally migrates toward the grain boundary such that this region may contain up to $5 \% \mathrm{Al}[9,10]$. The $\mathrm{SiC}-1$ has a crystal structure of 4 -H polytype $\alpha$-SiC. In SiC-2, the $\mathrm{B}$ additive remains evenly distributed throughout the grain, with a 6-H polytype $\alpha$-SiC crystal structure [11]. Of the two, the SiC-2 would be expected to deform plastically more than the SiC-1 because the $6-\mathrm{H}$ structure has a lower critical resolved shear stress (CRSS) than does the 4-H structure [12].

The $\mathrm{Al}_{2} \mathrm{O}_{3}$ materials were selected for three reasons. First, the single-phase $\mathrm{Al}_{2} \mathrm{O}_{3}$ materials are more ductile than single-phase $\mathrm{SiC}$ materials in general. Secondly, two $\mathrm{Al}_{2} \mathrm{O}_{3}$ materials were available with different grain sizes. Thirdly, $\mathrm{Al}_{2} \mathrm{O}_{3}$ is available with a glassy grain boundary phase, which is convenient to compare with the singlephase material. These features, and the mechanical properties measured by the manufacturer, are given in Table 1. On the basis of the data in Table 1, values have been calculated using eqn. (1) for prediction of the relative wear rates of these materials.

\subsection{Tests}

Two kinds of tests werc done to investigate the damage and wear modes in the materials described above. These were (1) static indentation tests and (2) sliding of a spherical indenter on the surface (scratch test). These tests have been found to produce similar kinds of damage and wear mode as in conventional long-term wear tests.

The indentation tests were done on a standard microhardness tester fitted with a Vickers diamond tip. A nurmal force of $10-100 \mathrm{~N}$ was used. The sliding tests were done on a CSEM scratch tester. A normal force range of 5-50 N, slider tip radius

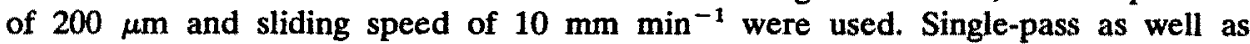
multiple-pass (up to five passes) tests were done. All the tests were done under ambient room conditions (relative humidity of about 20\%) and on smooth polished 


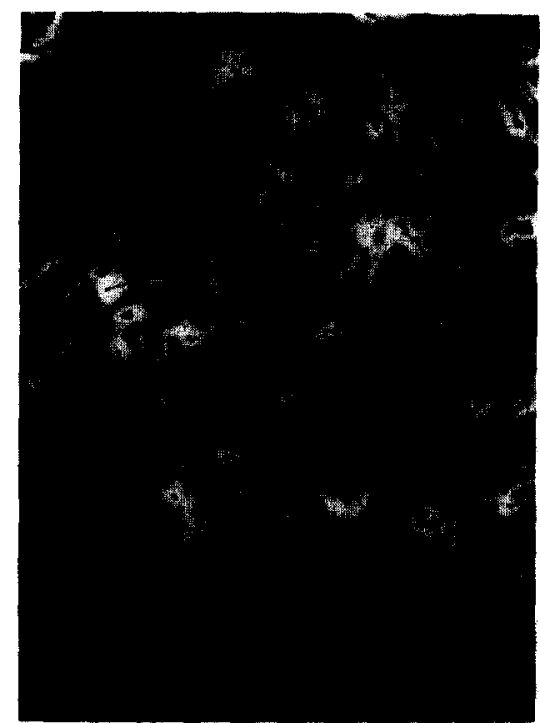

(a)

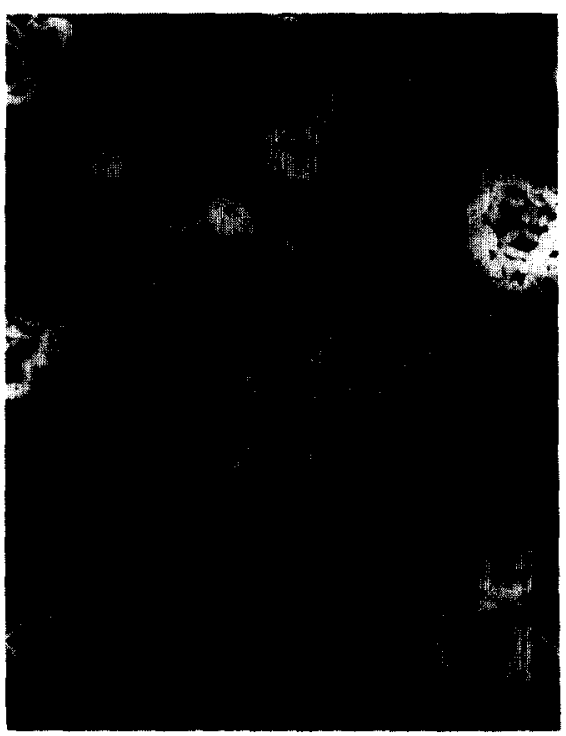

(c)

Fig. 2. SEM micrograph of the microstructure of the $\mathrm{Al}_{2} \mathrm{O}_{3}$ materials: (a) ALU1; (b) ALU2; (c) ALU3.

surfaces. With these test conditions, the amount of frictional heating is negligible since the sliding speed is low. Also the duration of the tests was very short such that tribochemical reaction, if any, was also negligible.

The frictional force was continuously monitored during the sliding tests. The dimensions of the damage produced by the slider were also measured using a surface 
TABLE 1

Some properties of the materials used in the present study

\begin{tabular}{|c|c|c|c|c|c|}
\hline & $\mathrm{SiC}-1$ & $\mathrm{SiC}-2$ & ALU1 & ALU2 & ALU3 \\
\hline Consolidation method & $\begin{array}{l}\text { Hot- } \\
\text { pressed }\end{array}$ & $\begin{array}{l}\text { Pressureless } \\
\text { sintered }\end{array}$ & Sintered & Sintered & Sintered \\
\hline Principal additive & $\mathrm{Al}$ & B & $\mathrm{MgO}$ & $\mathrm{MgO}$ & $\mathrm{SiO}+\mathrm{MgO}+\mathrm{CaO}$ \\
\hline Hardness $H(\mathrm{GPa})$ & 28.5 & 34.0 & 15.7 & 17.0 & 9.4 \\
\hline Young's modulus $E$ (GPa) & 435 & 410 & 372 & 372 & 220 \\
\hline $\begin{array}{l}\text { Fracture toughness } K_{\mathrm{tc}} \\
(\mathrm{MN} \mathrm{m}-3 / 2)\end{array}$ & $\begin{array}{l}3.54 \\
\approx 1.5\end{array}$ & $\begin{array}{l}3.23 \\
\approx 2.7\end{array}$ & $\begin{array}{l}3.52 \\
\approx 4.0\end{array}$ & $\begin{array}{l}3.53 \\
\approx 6.0\end{array}$ & $\begin{array}{l}3.55 \\
\approx 2.6\end{array}$ \\
\hline Grain size $(\mu \mathrm{m})$ & 3.3 & 3.1 & 3.9 & 3.9 & 3.7 \\
\hline $\begin{array}{l}\text { Density }\left(\mathrm{g} \mathrm{cm}^{-3}\right) \\
V \text { (from eqn. (1)) }\end{array}$ & 0.63 & 0.495 & 1.28 & 1.15 & 1.75 \\
\hline
\end{tabular}

profilometer. By taking a trace across the scratch, the width and depth of the damage were determined. All the tested specimens were examined by both optical and scanning electron microscope (SEM). The specimens examined in the SEM were all coated with a thin layer of $\mathrm{Au} / \mathrm{Pd}$ to prevent charging.

\section{Results}

\subsection{Indentation}

The characteristic radial cracks usually formed at the corners of an indentation were observed in all five materials for all loads used in the present test. The radial cracks in almost all cases propagated well beyond the contact region between the indenter and the material surface. The cracks followed the grain boundary (intergranular) in all the materials, except for SiC-2 ( $\alpha$-sintered SiC) where cracks propagated transgranularly.

In addition to the radial cracks, other kinds of damage occurred at and around the contact area. In general, the two SiC materials showed more fracture and fragmentation and less deformation around the contact area than the $\mathrm{Al}_{2} \mathrm{O}_{3}$ materials. From the hardnesses of the various materials in Table 1, more deformation is expected in the $\mathrm{Al}_{2} \mathrm{O}_{3}$ materials than the $\mathrm{SiC}$. Figure 3 shows the major features of the indentation damage in the two $\mathrm{SiC}$ materials. In the $\mathrm{SiC}-1$ material, extensive grain boundary failure occurred which resulted in the removal of some material from the contact area. This observation is in agreement with previous studies with this material [13, 14]. In SiC-2, extensive cracking was also observed around the contact area but it was primarily transgranular, as were the radial cracks. Evidence of a limited amount of plastic flow was also observed (Fig. 3(b)). Etching of an indented specimen showed more clearly the transgranular path of cracks in this material (Fig. 3(c)). In addition to the radial cracks, "rim" cracks were also revealed by the etching process.

Differences were also seen in the nature of the damage in the vicinity of indentation contact for the three alumina materials. In general, all three alumina materials showed evidence of plastic flow, with ALU3 showing the most, but in addition, extensive grain boundary cracking occurred in the ALU1 and ALU2 materials without loss of material 


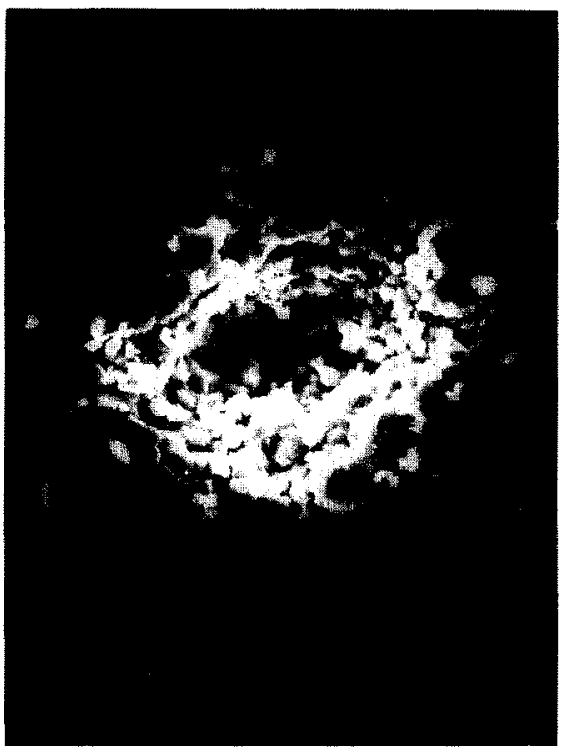

(a)

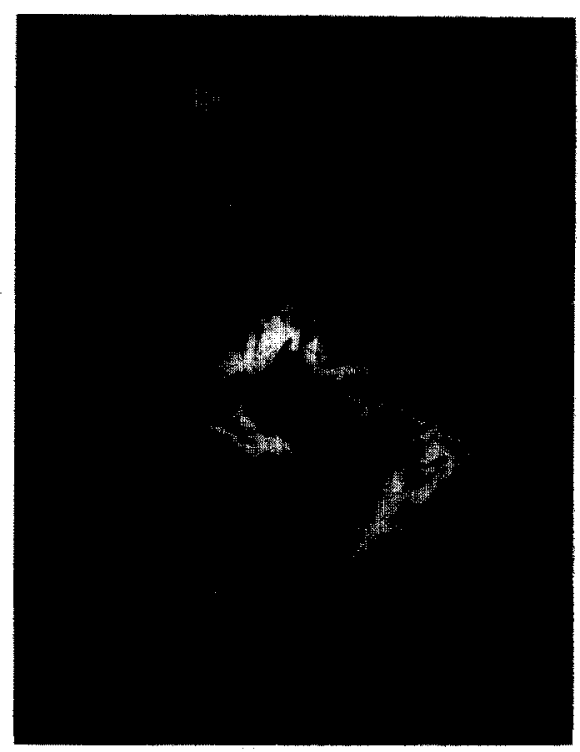

(b)

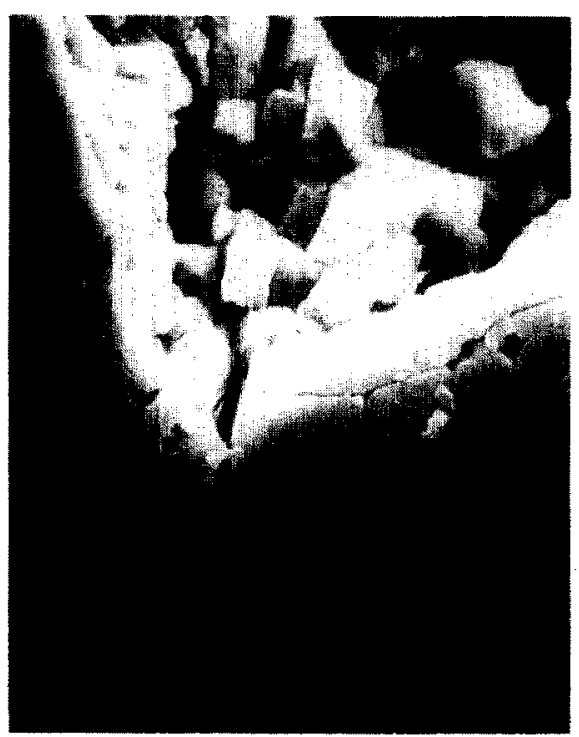

(c)

Fig. 3. Indentation damage in the two kinds of SiC materials: (a) hot-pressed SiC; (b) $\alpha$-sintered $\mathrm{SiC}_{;}$(c) etched $\alpha$-SiC material showing the transgranular nature of the cracks.

(Fig. 4(a)). Such cracking was not observed in ALU3 within any of the load ranges tested in the present work (Fig. 4(b)). Although the alumina materials showed more plasticity than the SiC materials, the grain boundary cracking observed in the ALU1 and ALU2 materials was very similar to that observed in the SiC-1 material. 


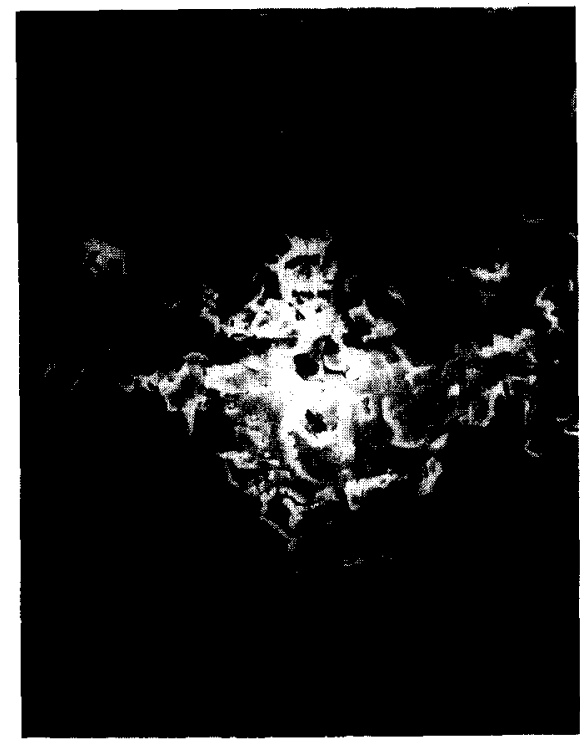

(a)

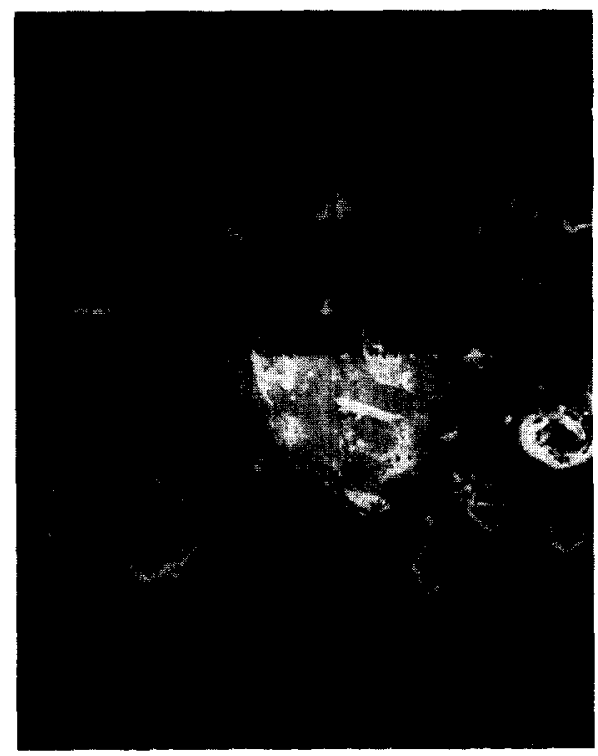

(b)

Fig. 4. Indentation damage in the alumina materials: (a) ALU1 and (b) ALU3.

\subsection{Sliding tests}

Figure 5 shows the frictional behavior of the five materials when sliding against a diamond indenter. The values plotted are the steady state friction coefficients. In all cases, the friction coefficient was lower than the steady value when sliding began. For all five materials, the friction coefficient appears to show a similar trend of modest increase with increasing load (Fig. 5(a)). Under repeat passes, however, significant differences were seen in the frictional behavior of the various materials. The two SiC materials showed increases in their friction coefficients with each pass; the increase was more pronounced in the SiC-1 material (Fig. 5(b)). The friction in the ALU1 and ALU2 materials increased for the first two passes, reached a peak at the third pass and then decreased thereafter. In the ALU3 material, after the first pass there was a small decrease in the friction coefficient to an almost constant value.

The frictional behavior appears to be connected with the nature of the damage. The materials in which fracture was prominent during contact exhibited an increase in the friction coefficient with repeat passes. The two SiC materials showed this trend. For materials in which both deformation and fracture were significant, only a slight increase in the friction with repeat passes was observed (ALU1 and ALU2). When deformation was the prominent mode of damage, the friction decreased modestly, rcaching a constant valuc with repcat passes (ALU3).

The damage produced by the diamond slider in all five materials was similar to that produced in the contact area during static indentation. These modes of damage have been observed to be the same as those occurring during sliding contact of the same ceramic material pairs with a cylinder-on-flat contact configuration [15]. The damage in the SiC-1 material consisted primarily of grain boundary failure resulting in the removal of grains with very little evidence of plastic flow (Fig. 6). As expected, the extent of the damage increased with increasing normal force. The extent of the 


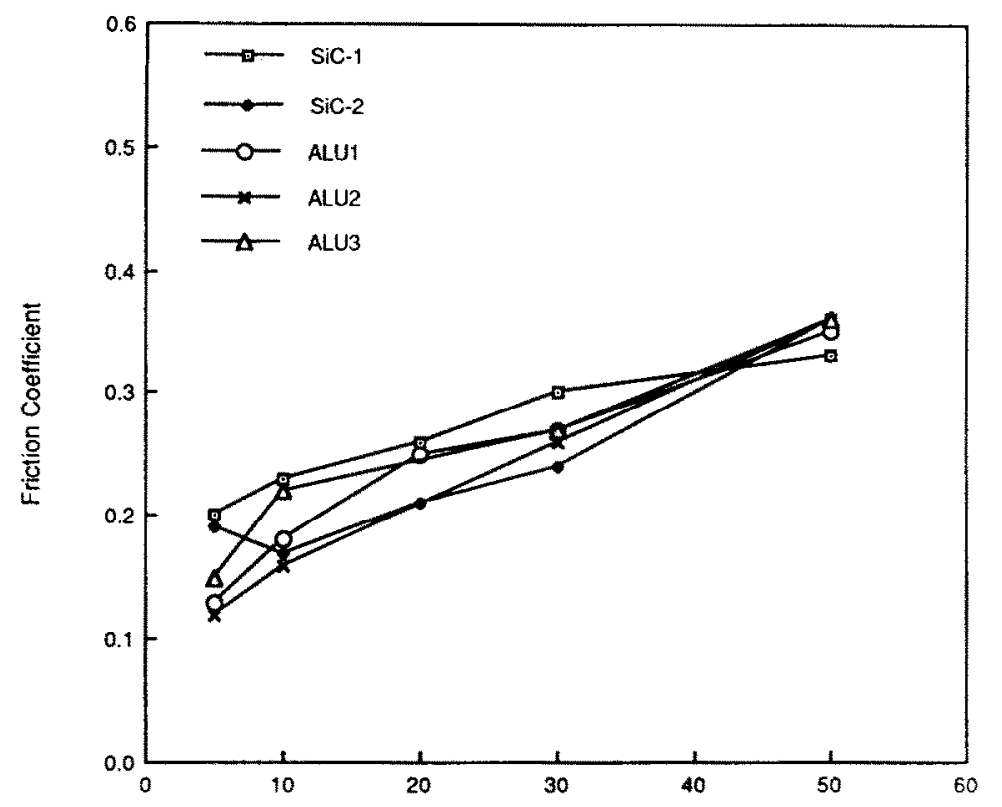

(a)

Normal Force (N)

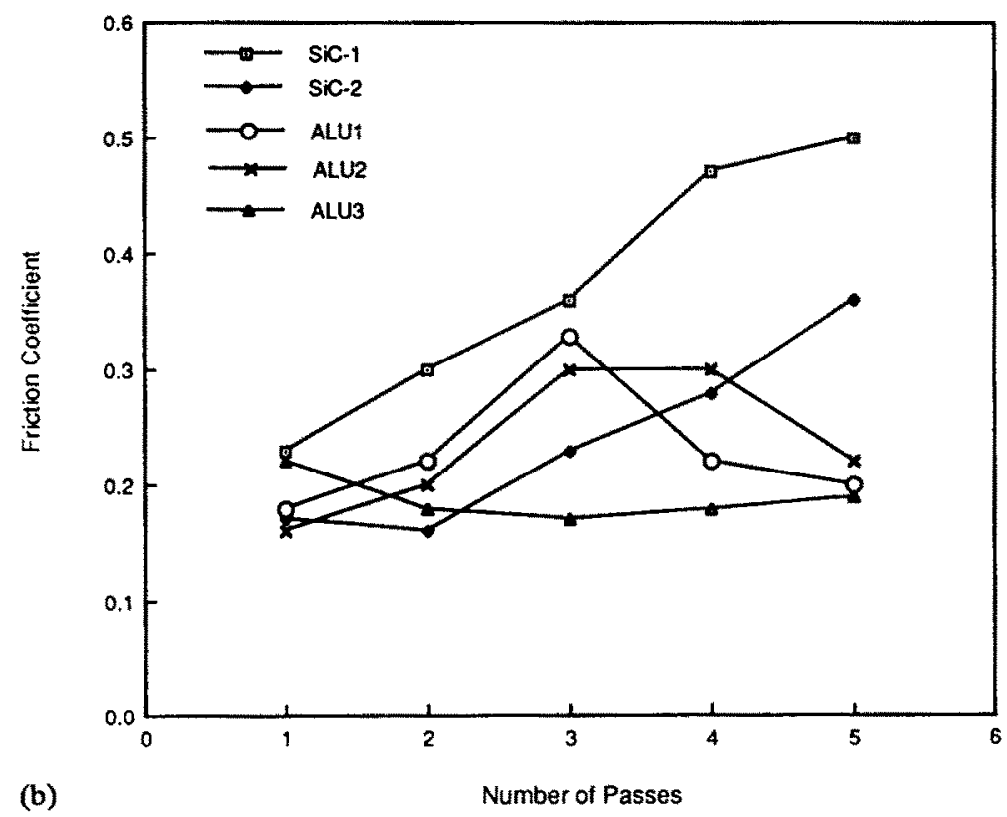

Fig. 5. Friction coefficient for a spherical tip diamond slider on the polished surface of the five different materials: (a) variation with normal force and (b) variation with the number of passes at a normal force of $10 \mathrm{~N}$. 


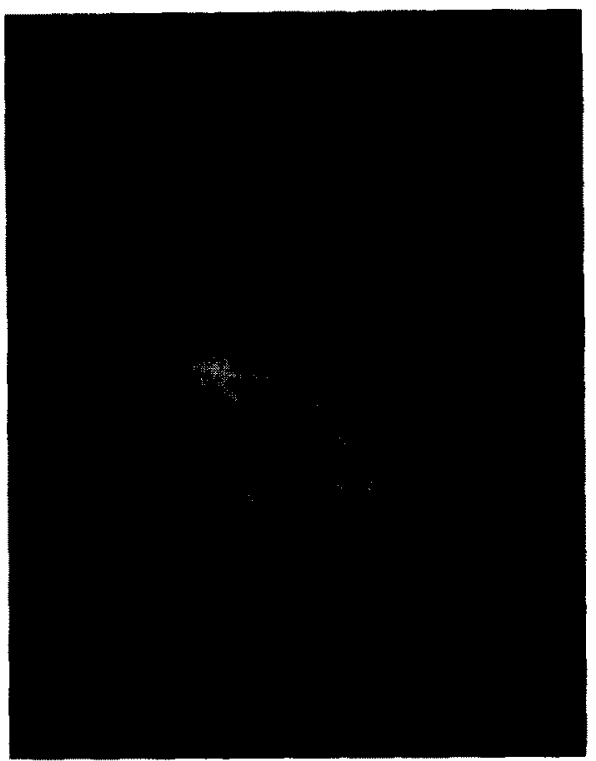

(a)

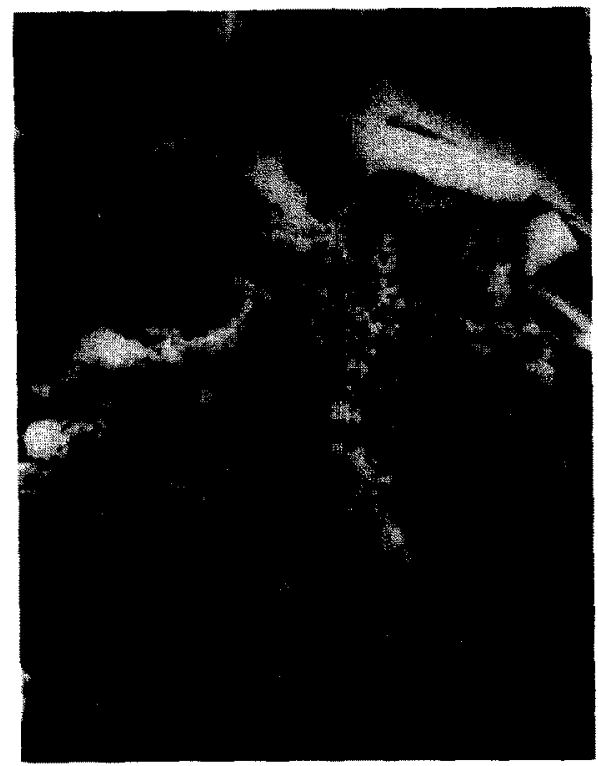

(b)

Fig. 6. Sliding indenter damage in the hot-pressed $\mathrm{SiC}$ material: (a) shows the occurrence of grain pluck-out and (b) fragmentation of the plucked grains to form the particulate.

damage also increased rather drastically with increasing numbers of passes at a constant load of $10 \mathrm{~N}$. An examination of the track after five passes showed that some of the displaced grains had undergone extensive amounts of cleavage to produce fine debris particles (Fig. 6(b)). In the SiC-2 material, no significant damage was observed until the normal force reached $20 \mathrm{~N}$ (see Fig. $7(\mathrm{a})$ ), when cracking outside the contact region was seen. At higher loads, these cracks extended into the contact region and some material was removed (Fig. 7(b)). After repeated passes at a low load of $10 \mathrm{~N}$, cracking on the track and material loss were eventually observed. In this material, the cracks formed appeared to follow the trajectory of the maximum tensile stress rather than the grain boundaries.

Figure 8 shows the damage in the alumina materials. ALU1 and ALU2 showed the same type of damage, consisting of some deformation and grain boundary cracking. Under repeated passes, material loss by grain pull-out was observed. The extent of the material removal was greater in ALU2 than ALU1 after five passes, although it started with less wear after a single pass (Fig. 9). The damage in ALU3 consisted primarily of plastic flow (Fig. $8(\mathrm{~d})$ ). Even at higher loads, only a limited amount of cracking at the edge of the track was observed.

Although the wear process is a very complex phenomenon that involves an interplay of several factors (and the prediction of long-term behavior with a short test should be done with caution), one could project the expected wear rate in the five materials from the dimensions of the damage track after repeat passes. This is due to the fact that the spherical indenter imposes the same kind of stresses as in a pin-on-disc wear tester. The dimensions of the tracks in each material after a single pass and after five passes of the slider are given in Table 2. This shows a comparison between different materials of the extent of the damage. 


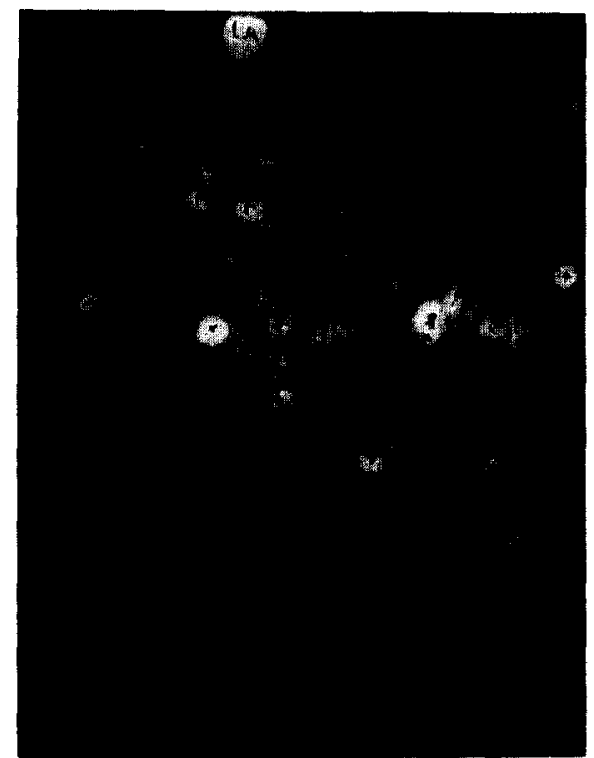

(a)

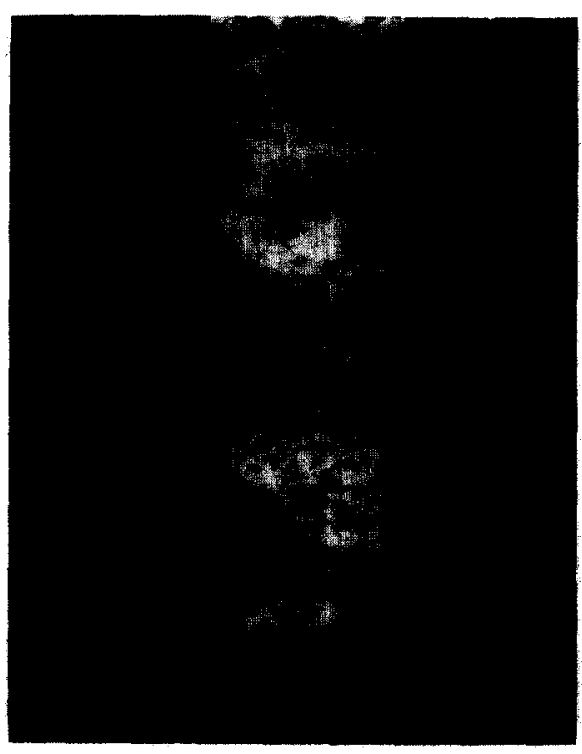

(b)

Fig. 7. Damage produced in the sintered $\alpha$-SiC material by a spherical tip slider showing (a) little damage at a load of $10 \mathrm{~N}$ and (b) cracking and some material removal at a higher load of $30 \mathrm{~N}$.

For a better visualization of the comparative amount of wear in the five materials, a plot was made of the track cross-sectional area as a function of the number of passes as shown in Fig. 9. A number of points can be seen in this plot. First, the ranking order of the materials by eqn. (1) is about the same as the results from onepass tests except for the ALU3 material. However, the equation predicts a total range of 2.6:1, whereas there is about a 1000:1 range in the data. It appears that the slight ductility and strong grain boundaries of the SiC-2 material are influential in its wear resistance. Ductility by itself is not beneficial as indicated by the higher wear of the $\mathrm{Al}_{2} \mathrm{O}_{3}$ materials in one-pass sliding as compared with the $\mathrm{SiC}$ materials.

The ranking order of the materials changes after five passes, reflecting the differences in the rate of progression of damage under cyclic stresses. The size of the increase in the wear over five passes was as follows: SiC-1 - 200 times; SiC-2 - more than 200 times; ALU1 - 7.5 times; ALU2 - 31 times; ALU3 - double. This suggests that the $\mathrm{SiC}$ materials are more prone to cyclic stress damage than the more "ductile" $\mathrm{Al}_{2} \mathrm{O}_{3}$ materials. ALU3 also showed the great influence of the glassy second phase in preventing a large increase in the wear rate after five passes.

\section{Discussion}

All ceramic materials show a general tendency toward brittleness under uniaxial tension and have a fracture strength determined by the flaw size and stress intensity factor of the material. Results from this study have shown that when under stress caused by sliding contact, the microstructure of the material has a very strong influence on the nature and extent of damage. We will now examine each material tested and the effect of various microstructural features. 


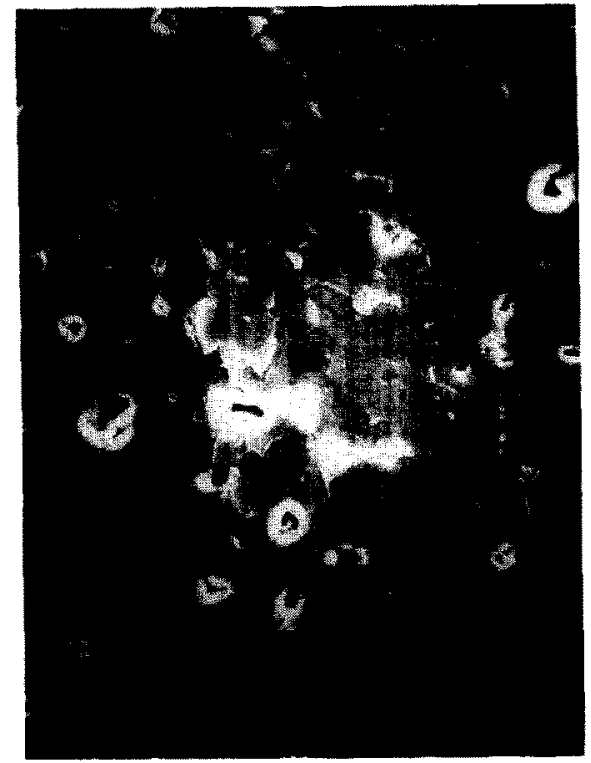

(a)

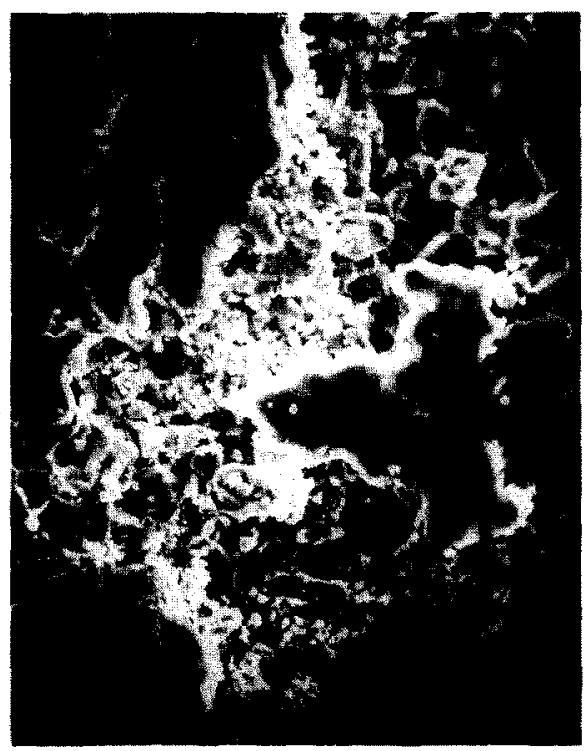

(c)

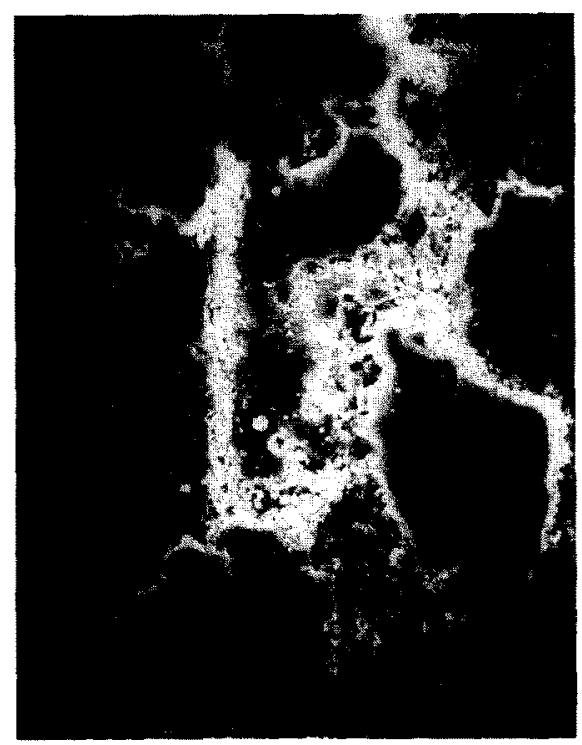

(b)

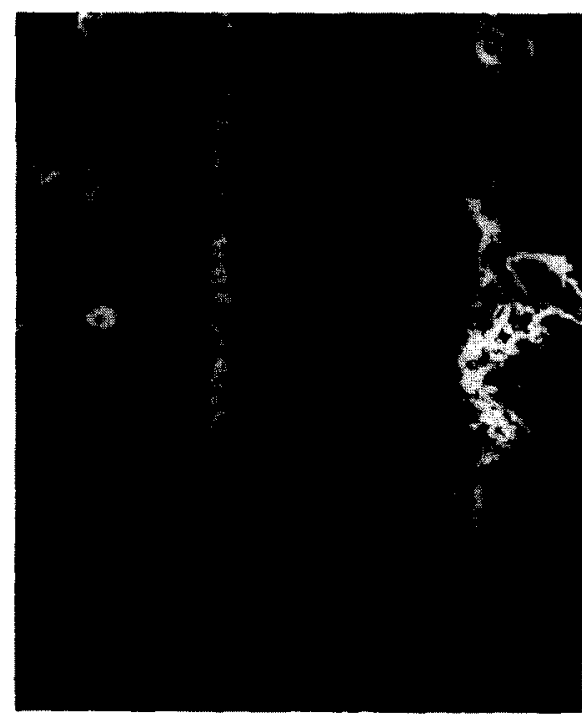

(d)

Fig. 8. Sliding indenter damage in the alumina materials: (a) ALU1; (b) ALU1 after five passes; (c) ALU2 after five passes; (d) ALU3.

The strain energy associated with imposed stresses on a material could be relieved either by plastic flow or by fracture, depending on the stress level needed to initiate each of the processes. In single-crystal materials, the flow stress (CRSS) and the cleavage stress determine which of the two processes dominates. The situation in a 


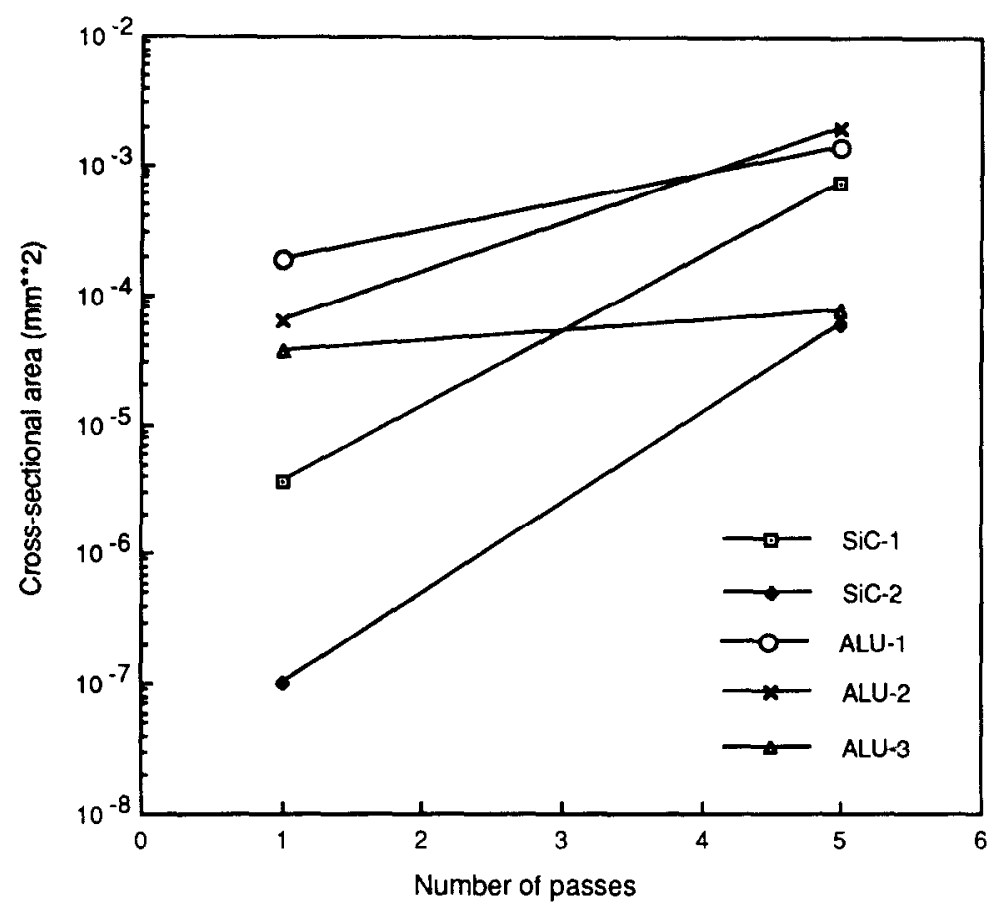

Fig. 9. Wear scar cross-sectional area as a function of the number of passes.

TABLE 2

The dimensions of the track produced during sliding indenter tests at a normal force of $10 \mathrm{~N}$

\begin{tabular}{llllllll}
\hline & 1 pass & & \multicolumn{5}{l}{5 passes } \\
\cline { 2 - 5 } \cline { 6 - 8 } & $\begin{array}{l}\text { Depth } \\
(\mu \mathrm{m})\end{array}$ & $\begin{array}{l}\text { Width } \\
(\mathrm{mm})\end{array}$ & $\begin{array}{l}\text { Cross-section area } \\
\left(\mathrm{mm}^{2}\right)\end{array}$ & $\begin{array}{l}\text { Depth } \\
(\mu \mathrm{m})\end{array}$ & $\begin{array}{l}\text { Width } \\
(\mathrm{mm})\end{array}$ & $\begin{array}{l}\text { Cross-section area } \\
\left(\mathrm{mm}^{2}\right)\end{array}$ \\
\hline SiC-1 & 0.1 & 0.03 & $3.70 \times 10^{-6}$ & 9.5 & 0.05 & $7.46 \times 10^{-4}$ \\
SiC-2 & $\mathrm{nd}^{\mathrm{a}}$ & $\mathrm{nd}^{\mathrm{a}}$ & $\mathrm{nd}^{\mathrm{a}}$ & & 0.75 & 0.05 & $5.89 \times 10^{-5}$ \\
ALU1 & 4.0 & 0.03 & $1.88 \times 10^{-4}$ & 9.0 & $\mathbf{0 . 1}$ & $1.41 \times 10^{-3}$ \\
ALU2 & 0.8 & 0.05 & $6.28 \times 10^{-5}$ & 12.5 & 0.1 & $1.96 \times 10^{-3}$ \\
ALU3 & 0.8 & 0.03 & $3.77 \times 10^{-5}$ & 1.2 & 0.04 & $7.54 \times 10^{-5}$ \\
\hline
\end{tabular}

and, negligible damage.

polycrystalline or multiphase material is complicated by the presence of the grain boundaries and second phases which may have properties significantly different from those of the grains.

The $\mathrm{SiC}$ materials in the present study best illustrate the effect of the grain boundaries. Although a $\{0001\}\langle 11 \overline{2} 0\rangle$ slip system has been reported for $\alpha$-SiC and some deformation observed [14], it is known that cleavage occurs more readily on the $(0001)$ plane in the presence of tensile stress. Plastic deformation of the $\alpha$-SiC crystal requires a high level of compressive stress owing to its high CRSS, which is typical 
of covalently bonded materials. Fracture is thus expected to be the dominating failure mechanism in the two SiC materials. A limited amount of deformation was observed in the regions subjected to high compressive pressure during indentation in the SiC2 material. This is because of the $6-\mathrm{H}$ polytype structure of $\mathrm{SiC}-2$, which has a lower CRSS than the 4-H polytype of the SiC-1 material [12]. This slight ductility has a significant influence on the wear rate.

In spite of the fact that fracture dominates in the $\mathrm{SiC}$ materials, the location and path of the cracks were different. In the hot-pressed material (SiC-1), fracture occurred along the grain boundaries resulting in "plucking" out of grains. This is a direct consequence of the segregation of the Al sintering aid toward the grain boundaries, resulting in a lowering of the fracture resistance of the boundaries $[9,10]$. This is akin to the embrittlement of iron by phosphorus or sulfur which segregates toward the grain boundaries. In the sintered $\alpha$-SiC material (SiC-2) doped with $\mathrm{B}$, there is no segregation of $B$ towards the grain boundaries; rather $B$ is uniformly distributed throughout the material $[10,11]$. Thus the grain boundaries are not necessarily the most brittle locations. In fact, in this material the fracture path was determined by the trajectory of the maximum tensile stress and the fracture was primarily transgranular. The two SiC materials have very similar properties, particularly hardness and fracture toughness (Table 1) but there is a significant difference in the amount of wear with a diamond slider (Table 2 and Fig. 9). This is due to the differences between the fracture modes of the two materials resulting from differences in their structure polytypes and their grain boundary chemistry and strength. The intergranular mode of fracture in the hot-pressed material will always result in grain pluck-out and removal, whereas the transgranular mode of fracture in the sintered $\alpha-\mathrm{SiC}$ material, which is not reflected in $H, E$, or $K_{c}$, does not necessarily result in wear. This leads to the much better wear resistance of the sintered $\alpha$-SiC material, despite the similarity in conventional properties.

The results from the alumina materials in the present study showed the effect of grain size and the presence of the second phase on the wear behavior of the materials. Single-crystal $\mathrm{Al}_{2} \mathrm{O}_{3}$ deforms by both twinning (basal $\langle 1100\rangle(0001)$ and rhombohedra $\langle 10 \overline{1} 0\rangle\{10 \overline{1} 2\})$ and slip. The basal $\langle 11 \overline{2} 0\rangle(0001)$ and the prism $\langle 1 \overline{100}\rangle\{11 \overline{2} 0\}$ slip systems have both been observed [16]. Deformation in $\mathrm{Al}_{2} \mathrm{O}_{3}$ at room temperature has only been observed under compressive stress.

Deformation and fracture in commercial polycrystalline alumina are not as easy to understand as with the single crystals because of the large variations in the $\mathrm{Al}_{2} \mathrm{O}_{3}$ materials. The ALU1 and ALU2 used in the present study are both essentially singlephase materials. Both of these deformed more than did the $\mathrm{SiC}$ materials which were also single-phase materials. In addition, an extensive amount of grain boundary failure occurred, resulting in grain pluck-out as was seen in the hot-pressed SiC material. The weakening of the grain boundaries in the alumina materials is due in part to the segregation of the sintering aid to the grain boundaries [17, 18] and in part to the anisotropic thermal expansion and elastic property of each grain. A residual tensile stress is imposed at some locations on the grain boundaries owing to the anisotropic thermal contraction of the grains upon cooling from the sintering temperature. The weakening of the grain boundaries is a cause of failure in addition to the deformation occurring in the grains. The material removal is, however, dominated by the failure of the grain boundaries. Thus we see similar wear mechanisms in these two $\mathrm{Al}_{2} \mathrm{O}_{3}$ materials and in hot-pressed $\mathrm{SiC}$, even though the $\mathrm{Al}_{2} \mathrm{O}_{3}$ materials showed more plastic flow. In spite of the similarity in damage mode, the rate of increase in wear during repeat passes was significantly different, ranging from more than 200 times for 
$\mathrm{SiC}-2$ to only 2 for ALU3 after five passes (Fig. 9). The more ductile $\mathrm{Al}_{2} \mathrm{O}_{3}$ materials in general showed lower rates of increase than the more brittle $\mathrm{SiC}$ materials.

ALU3 is a two-phase material with a substantial amount of amorphous glassy phase along the grain boundaries. This grain boundary phase is capable of viscous (plastic) flow. It could therefore accommodate the anisotropic nature of the $\mathrm{Al}_{2} \mathrm{O}_{3}$ grain deformation in addition to reducing the residual stresses at the grain boundaries. This accounts for the larger amount of deformation and lack of grain pluck-out that was observed in this material. If the stresses are high enough, failure will eventually occur in the glassy phase. Thus we see that the presence of a second softer phase can change completely the damage mode and amount of wear in a ceramic material.

It was observed in all the materials tested that the extent of damage increased with repeat passes. This progression of damage points to a fatigue process which is now being actively studied in ceramic materials (see e.g. refs. 19-21). Not much information is yet availablc on the fatiguc properties and behavior of ceramic materials; however, the results of the present study showed the important influence of this phenomenon on the wear of ceramics. The results of this work showed that singlephase ceramic materials are more susceptible to fatigue and thus to accelerated wear, whereas materials with a softer glassy grain boundary phase are resistant to fatigue damage. This may be due in part to the accommodation of the cyclic strain by the grain boundary phase. Also, the lower friction coefficient observed within the material reduces the damaging tensile stresses. The results also showed that the more ductile ceramic materials are more resistant to fatigue damage and more wear resistant than the brittle ones. This topic requires further study.

The present study has shown the very important effect of the microstructure on the tribological performance of ceramic materials. Ceramics with similar mechanical properties were observed to show very different wear modes and amounts of damage, primarily because of differences in their microstructures. It is "easier" and often more attractive to specify a property or combination of properties, usually mechanical, that determine the wear behavior in a material. For ceramic materials, fracture toughness and hardness are the chosen properties. This study has shown, however, that the microstructure may be more important than a single such property. All the materials used have about the same fracture toughness; the hardnesses of the SiC materials are similar to each other, as are those of the alumina materials to each other. Nevertheless, significant differences were seen in their wear modes and amounts.

\section{Conclusion}

Results from the present study showed that the mode and to some extent the amount of wear in a ceramic material is very dependent on the microstructure of the material. Using two kinds of $\mathrm{SiC}$ materials with similar mechanical properties and three types of alumina materials with some similar properties, differences in wear behavior were observed. Intergranular fracture controls the wear in materials with weaker grain boundaries; the amount of wear is also more than that in materials where it is controlled by transgranular fracture. Further, the presence of a second amorphous grain boundary phase promotes more plastic flow and less wear than in a similar material without any such second phase. All the materials except ALU3 were observed to undergo fatigue damage during repeat passes of a slider, with the damage more prominent in materials that fail primarily by intergranular fracture. 


\section{References}

1 A. G. Evans and D. E. Marshall, in D. A. Rigney (ed.), Fundamentals of Friction and Wear of Materials, American Society for Metals, Metals Park, OH, pp. 439-452.

2 T. A. Libsch, P. C. Becker and S. K. Rhee, Wear, 111 (1986) 263.

3 M. A. Moore and F. S. King, Wear, 60 (1980) 123-140.

4 B. J. Hockey, J. Am. Ceram. Soc., 54 (1971) 223-231.

5 D. C. Cranmer, J. Mater. Sci., 20 (1985) 2029-2037.

6 C. S. Yust and F. J. Carignan, ASLE Trans., 28 (1984) 245-252.

7

8

9 Y. Tajima and W. D. Kingery, J. Mater. Sci., 17 (1982) 2289-2297.

10 R. Hamminger, G. Grathwohl and F. Thummler, J. Mater. Sci., 18 (1983) 353-364.

11 G. H. Wroblewska, E. Nold and F. Thummler, Ceram. Int., 16 (1990) 201-209.

12 K. Meada, K. Suzuki, S. Fujita, M. Ichiharo and S. Hyodo, Philos. Mag. A, 57 (1988) 573-592.

13 O. O. Ajayi and K. C. Ludema, Wear, 124 (1988) 237-257.

14 O. O. Adewoye and T. F. Page, Wear, 70 (1981) 37-51.

15 O. O. Ajayi, Ph.D. Thesis, University of Michigan, Ann Arbor, 1989.

16 R. M. Cannon, Adv. Ceram., 10 (1983) 818-838.

17 G. DeWith, J. Mater. Sci., 19 (1984) 2195.

18 R. S. Jupp, D. F. Stein and D. W. Smith, J. Mater. Sci., 15 (1980) 96.

19 H. N. Ko, J. Mater. Sci. Lett., 5 (1986) 464-466.

20 S. Suresh, Int. J. Fract., 42 (1980) 41-56.

21 R. H. Dauskardt, W. Yu and R. O. Ritchie, J. Am. Ceram. Soc. C, 70 (1987) 248-252. 